\title{
2. THE DEVELOPMENT OF TECHNOLOGY EDUCATION INTERNATIONALLY
}

The last 15-20 years have seen the emergence of technology as an area of study in its own right and the development of school curricula in Australia, the United Kingdom, USA, Canada, Europe, South Africa, and New Zealand that emphasise the importance of students developing technological literacy.

The development of technology education within countries and regions is set within the historical, cultural, and political environment. Curriculum, teacher education, and in fact educational research do not sit in isolation from these. Each of the chapters in this section sets out the context for technology education in its respective country and provides a historical and political analysis of the development of technology education as a field of development. The history of technology education is a long one if we consider its development back to the days of craft, and in this section many of the chapters trace the journey from craft through to much broader notions of technology and technological literacy.

In Chapter 3, Clare Benson explores the development of design and technology in the curriculum of England. She traces the development of over 50 years, through the different political and educational agendas from the 1950s until the mid 2000s. The subject of craft, design and technology (CDT) was developed in the 1980s to expand the notion of craft, with its gendered and set pieces to include planning and thinking. However, national assessment and/or monitoring can have a large impact on the possible development and implementation of a new subject and Clare highlights the influence of the Assessment Performance Unit on the development of design and technology curricula. In addition, external professional bodies such as Design Councils and engineering groups can act as advocates for a curriculum, but also limit its development.

Literacy and numeracy initiatives as well as over-crowded curriculum can lead to a reduction in curriculum time in 'new' subject areas such as technology, particularly in primary schools. Different subject subcultures also influence the interpretation of a curriculum area like technology, which can be perceived as an applied science or craft depending on the background of the teacher (Jones, 1997). Clare highlights the different influences on the 1990s curriculum revisions in England and the fact that there was little professional development available for teachers. She concludes that whilst good practice in design and technology is developing in England, teacher knowledge remains a significant barrier to effective national practice.

Jacques Ginestié in Chapter 4 presents the ways in which technology education is represented in France, particularly with respect to technology education research. Jacques also highlights the way that more dominant subject subcultures can influence how technology education is perceived and operationalised in curricula and research. The identification and articulation of knowledge suitable for technology education is an open-ended problem and highlights the fragility of technology education. However, although Jacques indicates that the emerging area of technology may be somewhat fragile in nature, there is a world wide movement to develop a more robust framework. 
Tapani Kananoja introduces an historical perspective to technology education in Finland in Chapter 5 and notes that the teaching of practical skills and technology in general education was evident in Europe as the early as the seventeenth century as 'education for work'. Handicrafts were included in the Finnish curriculum in 1866, reflecting the main aim of the curriculum as training the future work force. Industrial arts were included in the 1920 s as the technical skills required for work changed.

Building on the notion of industrial arts, William (Bill) Dugger analyses the development of technology education in the United States of America in Chapter 6, noting that in industrial arts evolved from manual arts in the late 1800s and early 1900s. 'Technology' was used in the 1970s and 1980 s by particular curriculum development projects. Although curriculum can be agreed at the national level in the USA, the way it is implemented - or even included - is defined at the State and even the school district level. The development of the national curriculum - Standards for Technological Literacy: Content for the Study of Technology [STS] (International Technology Education Association [ITEA], 2000/2002/2007) - is discussed in detail. Very rarely do we get such an insight into the development of a national curriculum from an insider's perspective, including the ways in which curriculum and stakeholders interact.

The STS makes a strong call to educators, engineers, scientists, mathematicians, and parents for the notion of 'technological literacy for all'. However, this is not federally mandated in the US, nor is it an actual curriculum for direct implementation in schools but rather a framework for developing a curriculum. The ITEA released Advancing Excellence in Technological Literacy in 2003. This document outlines the standards and principles in relation to assessment, professional development, and programme implementation. The integration of these is one of the strengths of this approach to curriculum. Too often in national curriculum development, their isolation becomes a barrier to successful implementation. Bill concludes his chapter with the sobering note that technology education and technological literacy will become a reality for our students of tomorrow only when the different sectors in the country work together to this end.

The implementation of the technology as a curriculum area is always diverse when a country's education system is run at the national and state/provincial/local level. This is true for Canada as well as the US, and in Chapter 7 Anne Marie Hill provides a thorough analysis of the recent research and development in the study of technology in Canada, with its 10 provinces and 3 territories. One of the interesting pieces of analysis to come through in commentaries and research evidence is that students enjoy technology as a subject in schools. Anne Marie provides an historical account of Canada to set the context for curriculum and curriculum development, illustrating the multifaceted nature of education in Canada and the political nature of curriculum development. Although most places internationally have had a history of technical education in secondary schooling and this has moved to broaden into technology education, Anne Marie highlights that if we are to have effective technology education in secondary schools we must start with effective technology education programmes at the elementary/primary end of the school system.

Australia is in some ways similar to Canada in that there is some federal influence on curriculum, although it is mainly a state responsibility. Howard Middleton in Chapter 8 outlines the development of technology as a key learning area at the national level, highlighting the importance of co-operation between researchers, administrators, schools, and teachers. He goes on to report on ways in which researchers are exploring issues in the teaching and learning of technology. The disconnection between having a curriculum but being slow to implement professional development opportunities for teachers is raised. As has been found in other countries, primary teachers are enthusiastic about technology whereas at the secondary school level there has been a much more mixed response. For effective implementation of technology, then, there not only needs to be effective teacher professional development, but effective 
pre-service teacher education programmes also need to be developed, including the appropriation of government scholarships to encourage people in to technology teaching. Although pre-service and inservice training are important aspects of curriculum implementation, Howard also highlights the productiveness of working collaboratively at the national, state, and local level to implement technology education. In the development and implementation of a new curriculum area there are always tensions and contradictions, particularly around general technology education and vocational education, shortening teacher education programmes, and more instrumental approaches to research.

Although New Zealand and Australia collaborate in areas of education, the national systems are different. Whereas Australia has a federal and state approach to education, New Zealand has a national approach due mainly to its small size. Like other countries, New Zealand has had a history of technical education and in fact has had a national curriculum since the late 1870s. Chapter 9 provides background on the education system both from a historical and more recent perspective. As in other countries, technology emerged as an area in its own right in the 1990s with the development of the national curriculum (which was reviewed from 2001), national research projects, and national assessment and monitoring. In 2006-2008 changes were made to the curriculum to reinforce the notion of technological knowledge and practice, as well as students developing an understanding of the nature of technology.

Associated with the development of the technology curriculum in NZ has been a significant increase in the technology education research over the last 20 years. From 1990 onwards there has been a developing postgraduate research culture in technology education, including a focus on classroom studies. In the early days of the implementation of the curriculum there was a strong national focus on professional development. However, this was only for a limited time. The area of senior secondary technology became a concern and significant resources were obtained to enhance this area. These resources have expanded beyond senior secondary school and have the potential to significantly enhance technology education in the lower secondary level. However, concern must be expressed about the pressures of major curriculum revision by primary teachers, particularly with emphases on literacy and numeracy. Like Australia, the government is responding to the technology teacher shortage by introducing scholarships for pre-service teacher qualifications. Specific attempts have been made to link research, teacher education, professional development, and the curriculum framework together. Only time will tell if this has been an effective way forward.

In Chapter 10, Chitra Natarajan and Sugra Chunawala outline the development of technology and vocational education in India, showing strong links between the two. Similar to other chapters, they provide an historical perspective of the education system through to its current structure. The link between the structure of schooling and the structure of work is an important context in this chapter. In terms of curriculum change, Chitra and Sugra highlight that the current education system does not necessarily encourage collaboration and that there is a tendency to shy away from radical changes. The possible breadth of technology education also causes some difficulties in implementation, as do the inclusion of creativity and choice. This chapter clearly articulates how historical, political, social, and environmental perspective can both facilitate and constrain curriculum change.

Similarly, in Chapter 11 Bangping Ding provides an historical and social analysis of technology education in China, where labour-technical education has been officially recognised as a school subject in primary and secondary schools since the 1980s. However, Bangping highlights that China is no different from other countries in experiencing difficulties implementing a new curriculum. In particular, the influence of exit examinations, the shortage of qualified teachers, lack of resources, the influence of parents, and assessment methods constrain implementation. Given the size of China, Bangping uses the examples of Shanghai and Beijing to describe the 
emergence of technology education in secondary schools and the growing influence to move away from technical skills to general technological literacy and replacing labour-technical education with technology education.

In Chapter 12 Andrew Stevens again highlights the ways historical and social issues influence curriculum development. South Africa has undergone radical political and social reform in the last two decades, with educational reform being part of this. Teacher education has also been restructured, impacting on the implementation of technology education. The country, as Andrew notes, is still in a period of transition.

Research has mainly focused on the development and implementation of the curriculum and this needs to expand to highlight a way forward for technology education in South Africa.

All curriculum development is set within the social and political fabric of a nation and or state, in fact all curricula are essentially political. The opportunities for research and development are also influenced by the political frame. This section provides a sound basis from which to interpret the development of technology education research, development, teacher education, and curriculum.

\section{REFERENCES}

Jones, A. (1997). Recent research in student learning of technological concepts and processes. International Journal of Technology and Design Education, 7(1-2), 83-96.

International Technology Education Association [ITEA]. (2000/2002/2007). Standards for technological literacy: Content for the study of technology. Reston, VA: Author.

ITEA. (2003). Advancing excellence in technological literacy: Student assessment, professional development, and programme standards. Reston, VA: Author.

Alister Jones

School of Education

University of Waikato

Hamilton, New Zealand 